Department ; and a collection of marine shells from the New Hebrides and New Caledonia, made and presented by Mrs. Georgina Mills.

\section{Electronic Computer for the Meteorological Office}

Aprroval has been given for the Meteorological Office to buy an electronic computer, and one has been ordered. The machine will be installed in the Napier Shaw Laboratory at the Central Forecast Office, Dunstable, and will be employed primarily on research into forecasting by numerical methods the space distribution of the height of selected isobaric surfaces which define the main features of the wind and temperature distribution up to some $10 \mathrm{~km}$. above the Earth. On the basis of this information, the experienced forecaster can make the forecasts of wind and weather. Experience has shown the prediction of the future pattern of atmospheric structure to be one of the most difficult parts of forecasting ; it is this part which electronic computers, by solving simplified forms of the dynamical equations of the atmosphere, can perform. Research into numerical forecasting has been conducted by the Forecast Research Division of the Meteorological Office for about eight years; but the Office has had to hire or borrow 'time' on the electronic computers belonging to others for actual trial of its methods. The computer will also be available for research into other complicated problems of meteorology, in which very heavy numerical work is involved.

\section{Soaps as Polyelectrolytes}

As a continuation of earlier seminars in the Chemistry Department of University College, London (Nature, 175, 670 ; 1955), Prof. J. J. Hermans, of the University of Leyden, gave a lecture on April 30 on polyelectrolyte properties of soaps. Debye's work (Ann. New York Acad. Sci., 51, 575 ; 1949), dealing with the light-scattering of dilute soap solutions, was discussed, both the merits and the shortcomings of this treatment being demonstrated. Hutchinson's conclusions (J. Colloid. Chem., 9, 191 ; 1954) neglect the fact that the system under consideration contains two solute components. Trap and Hermans (Kon. Ned. Akad. Wet. Amsterdam, B, 58, No. 2 ; 1955) carried out some accurate light-scattering measurements from which it follows that certain dilute soap solutions, in the presence of $0.05 M$ potassium chloride, contain rod-shaped micelles about $1000 \mathrm{~A}$. long. This is consistent with earlier results of Debye and Anacker (J. Phys. Coll. Chem., 55, 644; 1951). In the discussion, Dr. G. S. Hartley mentioned that the possibility of rod-shaped soap micelles had been considered by him in 1939, and Dr. J. H. Schulman referred to his recent work on surface tension. Other participants in the discussion directed attention to peculiar observations during the passage of soap solution through membranes. Finally, the question was discussed as to whether the intrinsic viscosity of soap solutions, determined at sufficiently low rates of shear with a Couette instrument, in conjunction with light-scattering experiments, might be helpful in estimating the size and shape of soap micelles. Such an approach would appear to be of interest, because of its success in the fields of other polyelectrolytes.

\section{Rearing Locusts in the Laboratory}

Ever since the days of T. H. Huxley, the standard introduction to the study of insect anatomy has been the dissection of the cockroach. Although large and easily obtainable, the cockroach is not an ideal insect for this purpose; the locust is better suited for teaching and for practice in elementary dissection. During recent years the locust has also proved increasingly useful for experimental work of many different kinds. The ease with which locusts can be reared in classroom or laboratory is not generally realized; it is therefore timely that the Anti-Locust Research Centre (1 Princes Gate, Kensington, London, S.W.7) should have produced a pamphlet, "Instructions for Rearing and Breeding Locusts in the Laboratory", by P. Hunter-Jones (pp. 9; 1956), which will be useful for both research workers and teachers. The easiest species to rear is the African migratory locust, Locusta migratoria, and most space is devoted to this; but the special requirements of the desert locust Schistocerca gregaria, the red locust Nomadacris and the Egyptian grasshopper Anacridium are briefly outlined. Copies of the pamphlet are obtainable on request from the Centre, which is often prepared to assist by supplying day-old hoppers for starting locust stocks.

\section{Griseofulvin and Pathogenic Fungi}

R. S. C. Aytoun has contributed some interesting information on the effects of griseofulvin on actively growing hyphae of phytopathogenic species of Botrytis, in vitro and in vivo (Ann. Bot., N.S., 20, $78,297 ; 1956)$. In vitro, the reactions noted were slowing of the growth-rate, stimulation of branching, abnormal appearance of hyphal protoplasm, and loss of rigidity of the hyphal membrane in the region of the tip. The antibiotic is not translocated within the mycelium. In vivo, Botrytis tulipae was incapable of penetrating cell membranes in the stem of tulips watered with griseofulvin. The antibiotic was shown to delay or to prohibit the penetration of onion epithelium by $B$. allii, depending on concentration. The characteristic curling and stunting of hyphae caused by griseofulvin have both been observed to occur in plant cells.

\section{Forestry Commission : Report for 1953-54}

The annual report of the Forestry Commission for the year ending March 1954 (pp. $177+8$ plates. London: H.M.S.O., 1955; 6s. net) contains an introduction by Mr. James Macdonald, director of research and education, outlining the three sections in which forestry research is considered in the report. The first section deals with brief summaries of the main trend of work proceeding in the Research Branch of the Commission; the second deals with projects under investigation by universities and other institutions; and the third, a new section, comprises a series of papers by members of the research staff on subjects which have yielded sufficient information to be made public in this form, although often the importance of the inquiry must be considered as provisional. This is a most useful departure; so often during a piece of research work being undertaken a point is reached at which it would be useful for both the research worker and others to know exactly how far the investigation has gone, and yet this cannot be made available in a research report since the knowledge available is not of sufficient detail. A list is added to the report of the more important experimental areas in Great Britain, classified under subjects. As the report shows, contact has been maintained with universities and institutions engaged on research in forestry and related subjects, such as the Rothamsted Experi- 